\title{
Review Article \\ Review on the Durability of Polypropylene Fibre-Reinforced Concrete
}

\author{
Yanzhu Liu $\mathbb{D}^{1},{ }^{1}$ Liang Wang $\mathbb{D}^{1,2}$ Ke Cao $\mathbb{D}^{1},{ }^{1}$ and Lei Sun $\mathbb{D}^{1}$ \\ ${ }^{1}$ School of Civil Engineering and Architecture, Anhui University of Science and Technology, Huainan, Anhui 232001, China \\ ${ }^{2}$ Huaibei Mining (Group) Co. Ltd., Huaibei, Anhui 235000, China \\ Correspondence should be addressed to Liang Wang; 824894000@qq.com
}

Received 2 December 2020; Revised 12 April 2021; Accepted 19 May 2021; Published 8 June 2021

Academic Editor: José Aguiar

Copyright (c) 2021 Yanzhu Liu et al. This is an open access article distributed under the Creative Commons Attribution License, which permits unrestricted use, distribution, and reproduction in any medium, provided the original work is properly cited.

Polypropylene fibre (PPF) is a kind of polymer material with light weight, high strength, and corrosion resistance. The crack resistance of concrete can be improved by adding PPFs. PPF can optimize the pore size distribution of concrete. As a result, the durability of concrete is significantly enhanced since PPF can block the penetration of water or harmful ions in concrete. This paper summarizes the influence of polypropylene fibre on the durability of concrete, including drying shrinkage, creep, water absorption, permeability resistance, chloride ion penetration resistance, sulfate corrosion resistance, freeze-thaw cycle resistance, carbonation resistance, and fire resistance. The authors analysed the effects of fibre content, fibre diameter, and fibre hybrid ratio on these durability indexes. The durability property of concrete can be further improved by combining PPFs and steel fibres. The drawbacks of PPF in application in concrete are the imperfect dispersion in concrete and weak bonding with cement matrix. The methods to overcome these drawbacks are to use fibre modified with nanoactive powder or chemical treatment. At last, the authors give the future research prospects of concrete made with PPFs.

\section{Introduction}

Polypropylene fibre (PPF) is a kind of linear polymer synthetic fibre obtained from propylene polymerization. It has some advantages such as light weight, high strength, high toughness, and corrosion resistance. The PPF is widely used in chemical industry, energy, clothing, environmental protection, and construction [1-6]. In the construction industry, concrete has the disadvantages of low tensile strength, weak deformation resistance, and poor crack resistance. The microcracks are easily produced from the outside to the inside, which increase the permeability of the concrete. Water or other harmful ions easily enter the interior of the concrete and accelerate the deterioration of the concrete [7]. When PPF is added in concrete, the threedimensional random distribution network structure can be formed in concrete, which effectively inhibit the microcrack generation and development [8-11]. As a result, the PPF can prevent water and other harmful ions entering into concrete. The durability of concrete can be improved by adding PPF
$[4,12-14]$. Due to the excellent properties, PPF can be used in architectural engineering, pavement engineering, and hydraulic engineering [7, 15-17]. In architectural engineering, the foundation construction of high-rise building needs to be poured mass concrete at one time. The mass concrete is easy to produce thermal cracks at the early age $[18,19]$. The PPF can effectively reduce the temperature cracks of the concrete [20]. Moreover, the resist-permeability of the concrete can be enhanced by adding PPFs due to less through cracks in the concrete [12, 21]. In pavement engineering, pavement often bears the impact load of vehicles, which requires good toughness and crack resistance, especially the pavement with large traffic volume or heavy loading traffic $[22,23]$. The PPF-reinforced concrete has better toughness than the plain concrete $[24,25]$. When PPF is used in concrete, the toughness of pavement can be significantly strengthened [7]. Meanwhile, less creaks are emerged under impact load of vehicles, indicating that the durability of pavement is enhanced by using PPFs in concrete $[26,27]$. Hydraulic engineering, such as the bridge, 
culvert, dock, and dam, is usually in contact with water. This requires the concrete to have good resist-permeability for flowing water and harmful ions. The PPF can effectively increase the resist-permeability of concrete and block the water and harmful ions invade in concrete through the creaks, suggesting that the performance of concrete can be enhanced by using PPFs $[14,28,29]$. Numerous researchers have done a lot of work on the influence of polypropylene fibre on the durability of concrete and gotten a series of important achievements. For example, Rashid [14] investigated the effect of PPF on durability properties, including water absorption, sorptivity, and chloride penetration. The results showed that the PPFs in concrete have positive effect on the durability of concrete in terms of sorptivity and water absorption. However, the addition of PPFs did not obviously affect the chloride penetration. Wang et al. [13] studied the durability indexes (drying shrinkage, alkali-silica reaction expansion, and frost resistance) of rubber concrete made with macrosynthetic PPFs. They concluded that the PPFreinforced rubber concrete has better durability than the plain concrete. Previous research showed that the incorporation of PPF with other fibre can further improve the mechanical strength and durability of concrete $[9,10,30]$. Liu et al. [31] attempt to study the mechanical strength of self-compacting lightweight concrete made with the steel fibres and PPFs. The results showed that the compressive strength, splitting tensile, and flexural strength were significantly increased by adding steel fibres and PPFs. Smarzewski et al. [25] used the PPF and steel fibre in ultrahigh-performance concrete to probe the influence of those two kinds of fibre on the sulfate surface wettability, freezethaw cycle resistance and corrosion resistance. They found that the durability of concrete can be enhanced by adding hybrid fibres. Ranjith et al. [32] investigated the durability of engineered cementitious composites reinforced by PPFs and glass fibres. The durability indexes, such as water absorption, chloride penetration, sulfate attack resistance, and acid attack resistance, were enhanced by using PPFs and glass fibres together. In addition, the drying shrinkage, creep, and fire resistance are closely related to durability of PPF-reinforced concrete. The durability is related to the ability of concrete to resist the action of environmental media and reflects the service performance of concrete. It can be seen from the previous research that the research on durability of PPFreinforced concrete has achieved systematic research results. This paper summarized the durability indexes of PPFreinforced concrete, including drying shrinkage, creep, water absorption, permeability resistance, chloride ion penetration resistance, sulfate corrosion resistance, frost resistance, carbonation resistance, and fire resistance. The law of polypropylene fibre in concrete durability was analysed. On this basis, we investigated and evaluated the influence of fibre content, length, and diameter on those durability indexes of PPF-reinforced concrete. The research results are conducive to a better understanding of the durability of concrete with PPFs. It will be helpful to the reasonable use of PPF to enhance the durability of concrete, which can decrease the carbon dioxide emissions in concrete engineering. The research results provide the basis for future study and increase PPF applications in concrete. This paper describes the shortcomings of PPF in concrete application and the corresponding countermeasures. It helps to overcome some major existing problems in the application of PPF in concrete. The future research prospects of PPF in concrete application were discussed. This review gives the directions for future research and contributes to solve the key scientific and engineering problems for PPF application in concrete materials.

\section{Effect of Polypropylene Fibre on Durability of Concrete}

2.1. Drying Shrinkage. The drying shrinkage is the phenomenon of concrete volume shrinkage caused by the evaporation of water in the air, which is an inevitable harmful volume change for concrete structure. The drying shrinkage of concrete is related to the moisture migration and pore characteristics in concrete. The PPFs are often used in concrete to prevent microcracking caused by the dry shrinkage.

Previous studies show that the drying shrinkage of concrete is significantly reduced by the use of PPFs. Leong et al. [33] adopt to use the PPF in lightweight concrete by volume content of $0.15 \%, 0.3 \%$, and $0.5 \%$. The results showed that the concrete with PPFs has positive effect on drying shrinkage reduction. Saje et al. [34] compared the shrinkage behaviour of high-performance concrete made with and without PPFs. The results indicated that the drying shrinkage was considerably reduced by adding PPFs. Meanwhile, the optimum content of PPFs ranges between $0.25 \%$ and $0.5 \%$ by volume when the shrinkage and workability were simultaneously considered. Alrshoudi et al. [35] tried to use the waste PPFs in prepacked aggregate concrete at the content of $0-1.2 \%$ by volume. The drying shrinkage of the concrete was decreased compare to the one without PPF. The drying shrinkage of the PPF-reinforced concrete showed the trend of decreasing first and then increasing. The concrete with $0.75 \%$ PPF has lowest drying shrinkage as shown in Figure 1. Meanwhile, the drying shrinkage of concrete can be further decreased by adding PPFs and steel fibres. Afroughsabet et al. [36] reported that the dry shrinkage of concrete can be greatly decreased by adding PPFs and steel fibres. They found that the lowest drying shrinkage can be obtained by mixing with $0.3 \%$ PPFs and $0.7 \%$ steel fibres. Up to $26 \%$ reduction in drying shrinkage stain can be achieved compared with the plain concrete.

The drying shrinkage of concrete can be reduced by adding PPFs since the PPFs can prevent the deformation of concrete caused by water evaporation. The drying shrinkage of PPF-reinforced concrete is affected by the fibre content. More reduction in drying shrinkage can be achieved by using PPFs and steel fibres.

2.2. Creep. Creep is the deformation of concrete that increases with time under constant load, which is an important content of concrete structure design and calculation. The 


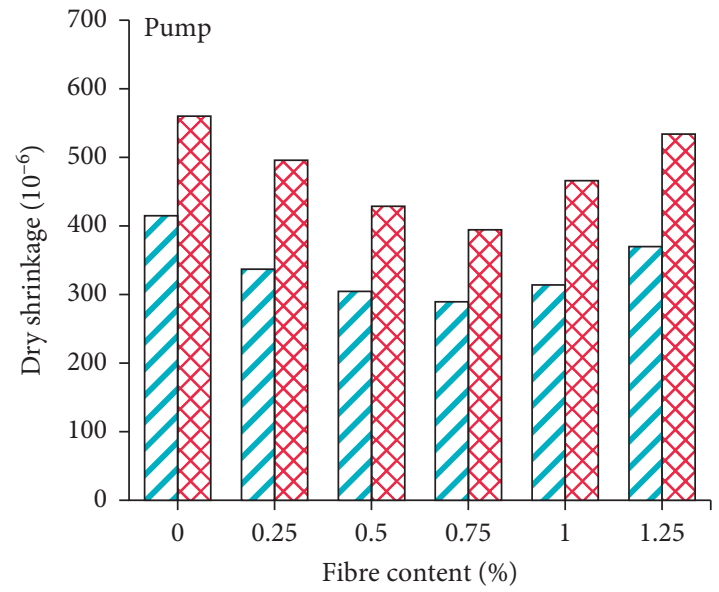

$\square 28$ days

Figure 1: Drying shrinkage concrete at 28 and 180 days [35].

main reason for concrete creep is the viscous flow and slippage of the hydrated gel. The creep is a crucial index to evaluate the concrete durability.

A few researchers have been investigated the creep of PPF-reinforced concrete. Vrijdaghs et al. [37] focus on the uniaxial tensile creep of cracked PPF-reinforced concrete. The results showed that the long-term tensile behaviour of the concrete was influenced by the load ratio. Alrshoudi et al. [35] compared the creep stain of concrete with and without waste PPF in the prepacked aggregate concrete. They found that the development trend of creep stain for the PPFreinforced concrete was only slightly smaller than the plain concrete. However, a few studies showed that the creep behaviour was not improved by using PPFs in concrete. For example, Lima et al. [38] explored the use of PPFs and steel fibres to define the influence on concrete flexural creep behaviour. The results showed that the concrete with PPFs has higher creep rate and deformation that the one with steel fibres. Some investigations aim to explore the effect of fibre types on the concrete creep. Aslani and Nejadi [39] used PPFs and steel fibres in self-compacting concrete. They found that the creep stain was increased by adding PPFs in concrete. However, the addition of those two types of fibres can reduce the creep strain of concrete. Zhao et al. [40] compared the effect of PPF, steel fibre, polyvinyl alcohol fibre, and basalt fibre on creep behaviour of concrete as shown in Figure 2. They concluded that the concrete creep can be resisted when the fibres had far higher elastic modulus than the plain concrete. The PPF, which was lower elastic modulus than the plain concrete, increased the concrete creep because the weaken interface structure between cement matrix and the firers has lower elastic modulus than that of plain concrete.

It seems that the addition of PPF has no positive effect on concrete creep. This probably attributes to the low elastic modulus of PPF. The creep stain can be reduced by using the fibre with high elastic modulus in PPF-reinforced concrete.

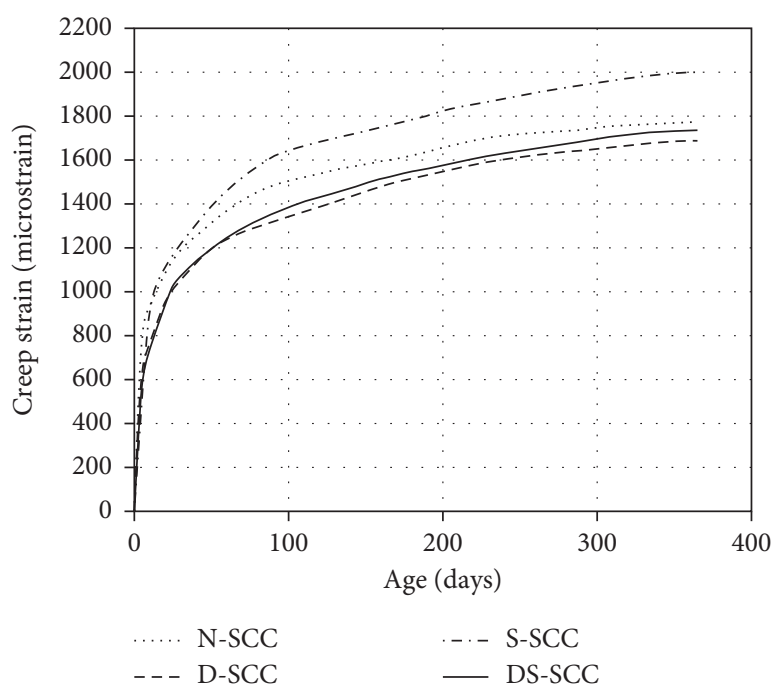

Figure 2: Creep stain for concrete with and without fibre [40].

2.3. Water Absorption. The penetration and transmission of water in concrete directly affect the durability of concrete. Some harmful substances can corrode the interior of concrete with water as the carrier. Therefore, water absorption is an important index to evaluate the durability of concrete. The addition of PPFs changes the pore structure and distribution of concrete and affects the water absorption of concrete.

The current research focuses on the influence of PPF content on the water absorption of concrete. Karahan and Atiş [41] found that the water absorption of PPF-reinforced concrete was higher than that of the concrete without fibres. The water absorption was increased with the PPF content because the addition of PPF increases the porosity. Yuan and Jia [42] compared the water absorption of concrete made with PPF (diameter $=0.06 \mathrm{~mm}$ ) and glass fibre. The concrete with PPFs had higher water absorption than the one with glass fibres, and the PPF-reinforced concrete was higher than the plain concrete when the volume content of PPF was more than $0.45 \%$. This is because of the hydrophobic nature of PPF, resulting in poor bonding performance with the cement mortar. In addition, excessive dosage of PPF probably leads to the inhomogeneity of the internal structure for concrete. However, some researchers have come to the opposite conclusion. Liu et al. [43] investigated on the capillary water absorption of PPF-reinforced concrete with slag and fly ash. The PPF with $0.035 \mathrm{~mm}$ diameter and $12 \mathrm{~mm}$ length was used at volume fraction of $0-1.35 \mathrm{~kg} / \mathrm{m}^{3}$. The capillary water absorption was decreased with the volume fraction due to the lower porosity of concrete with PPFs as shown in Figure 3. The opposite conclusion probably attributes to the fineness of PPFs. Afroughsabet and Ozbakkaloglu [44] investigated the water absorption of high-strength concrete with PPFs (diameter $=0.022 \mathrm{~mm}$ ) and steel fibres. The PPFs with $0.022 \mathrm{~mm}$ diameter and $12 \mathrm{~mm}$ length were used at volume content of $0.15 \%, 0.3 \%$, and $0.45 \%$. The results presented that the water absorption of 


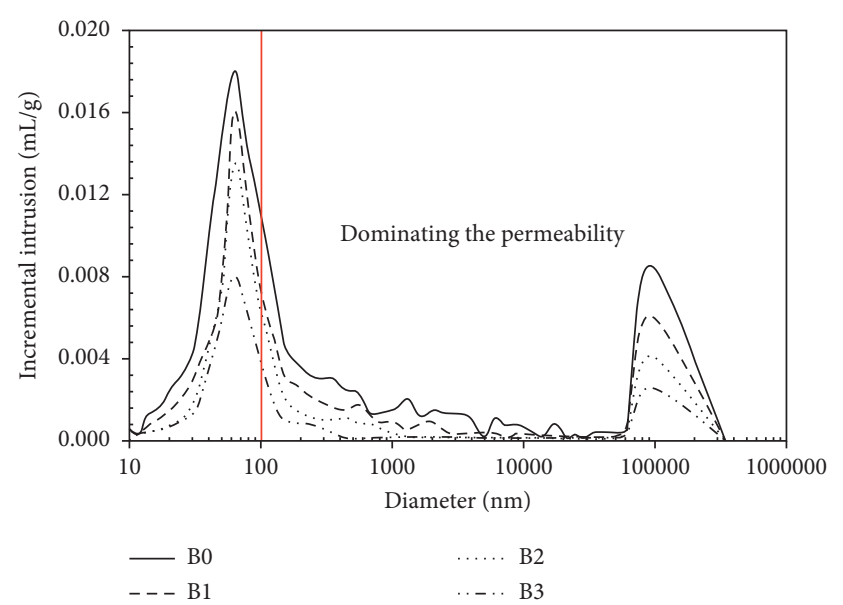

(a)

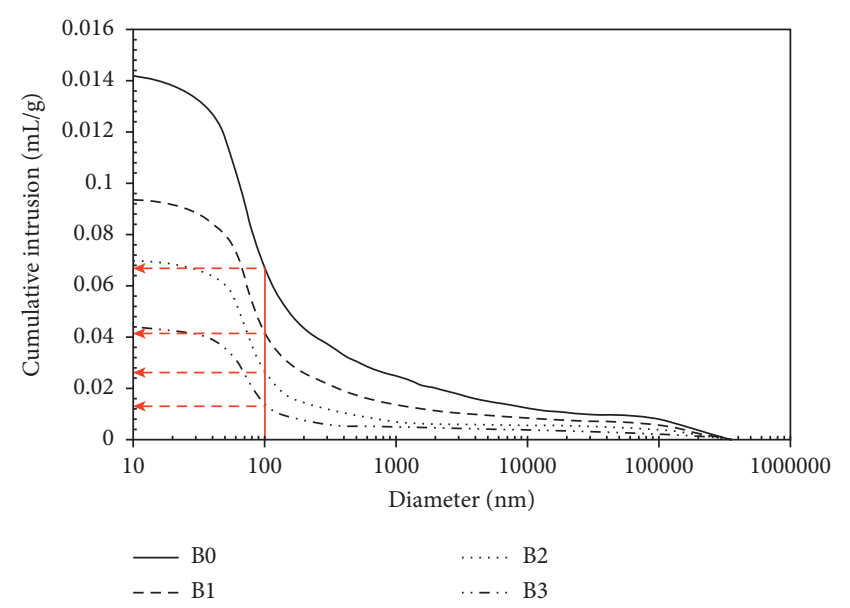

(b)

FIgUre 3: Pore size distribution of concrete with and without PPF [43].

PPF-reinforced concrete was decreased by the PPF content. The combined use of PPFs and steel fibres can obtain low water absorption concrete.

The water absorption of concrete is affected by the fibre content and fineness. The suitable PPF diameter and dosage can optimize the pore structure of concrete. The water absorption of concrete can be reduced by using finer PPF with suitable dosage. Moreover, the PPF-reinforced concrete is further reduced by adding steel fibres.

2.4. Permeability. In the fresh stage of concrete, the surface moisture of concrete is rapidly evaporating with large dry shrinkage. The microcracks are easily produced on the surface of concrete during the fresh stage. When PPFs are added in concrete, the segregation can be reduced and decrease the water evaporation. Moreover, PPF can effectively prevent the crack from developing from outside to inside of concrete. The permeability resistance of concrete can be improved by adding PPFs.

Some investigations showed that PPF can effectively prevent the segregation of fresh concrete and improve the uniformity of concrete mixture $[45,46]$. At hardened stage, the concrete with PPFs has less cracks, and the creaks in concrete were smaller and finer than the concrete without PPF. This suggests that the PPF can reduce the possibility of microcrack coalescence in concrete and significantly improve the permeability of concrete $[12,47,48]$. Ramezanianpour et al. [49] studied the influence of PPF weight content at the range of $0.5 \%-4 \%$ on the water permeability of concrete. The results showed the water penetration depth of concrete decreases by adding PPFs. Moreover, the water penetration depth was first decreased and then increased with the PPF content. The concrete with PPF content of $0.7 \mathrm{~kg} / \mathrm{m}^{3}$ has minimum depth of penetration, which is $30 \%$ lower than the one without PPF. Behfarnia and Behravan [15] investigated fibre-reinforced concrete used in water tunnels. They compared the water absorption of concretes with PPFs and steel fibres by volume content at the range of $0.4 \%-0.8 \%$. Up to $45 \%$ decrease in water absorption had been reached by using PPFs, indicating that the impermeability of concrete was significantly enhanced. Meanwhile, the steel fibre had more effect in reducing water absorption compared with PPF. Guo et al. [50] analysed the influence of multisize polypropylene fibre on the impermeability of concrete. The results show that fine fibres with diameter of $0.026 \mathrm{~mm}$ and $0.1 \mathrm{~mm}$ have obvious inhibition on micropores, while coarse fibres with diameter of $0.8 \mathrm{~mm}$ have more obvious inhibition on macropores. Moreover, the concrete mixed with coarse and fine PPFs has higher impermeability than the concrete with single diameter PPFs. The compressive strength of concrete has a linear relationship with the logarithm impermeability coefficient as shown in Figure 4. Li and Liu [12] pointed out that the cracks were more tortuous and the crack surface was rougher with the increase of polypropylene fibre content. Li et al. [48] investigated the influence of fibre diameter, length, and content on the impermeability of ultra-high-strength concrete. The results show that increasing the fibre length or the ratio of fibre diameter to fibre diameter can enhance the impermeability of ultra-high-strength concrete. Meanwhile, the inhibition of crack development in concrete is inhibited more obvious with the increase of fibre content and fibre length, as shown in Figure 5. However, the research results of Islam and Das [21] showed that the permeability of concrete increases with the increase of PPF content. The author believed that this phenomenon exists probably due to excessive fibre content.

The impermeability of concrete is affected by fibre content, diameter, length, and other factors. In a certain range, the impermeability increases with the fibre content and decreased with the fibre diameter. Therefore, generation and development of concrete cracks can be effectively inhibited by adding reasonable fibre diameter and fibre content.

2.5. Resistance to Chloride Penetration. Chloride ions invade into concrete through penetration, diffusion, and capillary action. The corrosion of reinforcement is accelerated when 


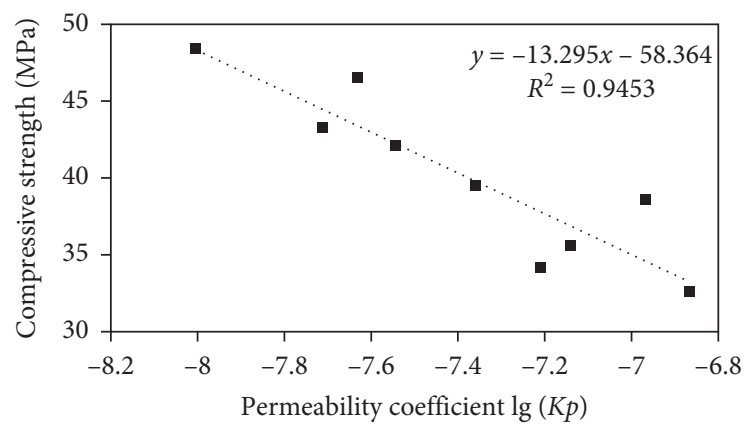

FIGURE 4: Permeability coefficient and compressive strength of concrete [50].

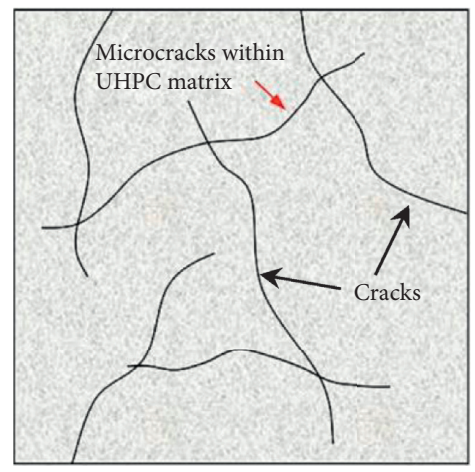

(a)

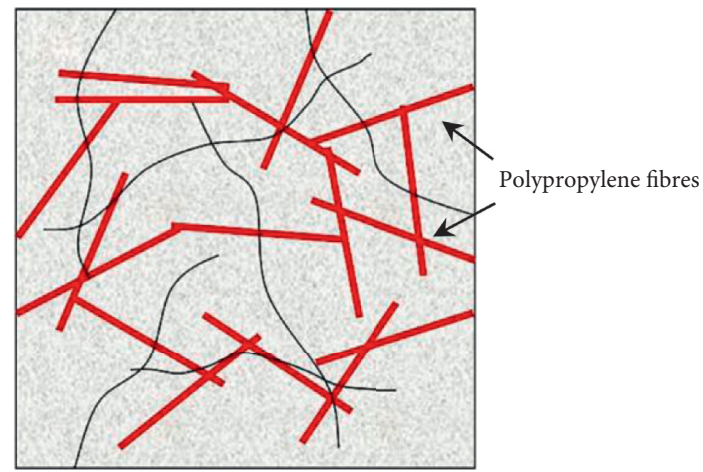

(b)

FIgURE 5: Schematic diagram of polypropylene fibre inhibiting concrete cracks [48].

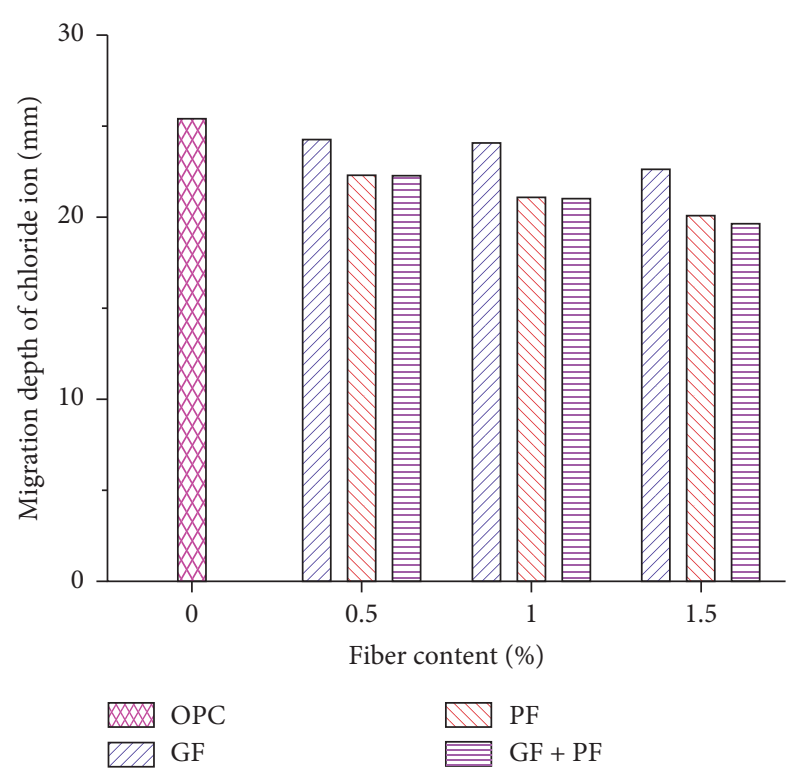

Figure 6: Chloride penetration depth [51].

chloride ions invade into concrete. The addition of fibre can optimize the pore size distribution and pore structure of concrete. The micropore in the concrete can be reduced and blocked by adding PPF, which reduces the probability of micropore penetration. As a result, the durability of concrete is significantly reduced.
The chloride ion penetration resistance of PPF-reinforced concrete is affected by the fibre content, length, diameter, and the proportion of coarse and fine fibres. The research results of Liu et al. [51] showed that PPF can inhibit the formation of shrinkage cracks, reduce the porosity of concrete, and improve the antipermeability ability of concrete. The penetration depth of chloride ion in concrete decreased with the content within 1.5\% PPF content by volume. Meanwhile, the improvement of polypropylene fibre on chloride ion penetration resistance was obviously better than that of glass fibre, as shown in Figure 6. Guo et al. [52] found that the electric flux of concrete decreased at first and then increases with the fibre content. This was because excessive PPF content decreased the workability of concrete, which reduced the bonding property between mortar and PPF. The pore in the interfacial transition zone (ITZ) between PPF and mortar provided channels for chloride ion penetration. Thus, the resistance of chloride ion penetration was decreased when adding excessive PPF in concrete. Liu and $\mathrm{Hu}$ [53] studied the influence of single fibre and mixed fibre on chloride ion penetration of concrete. For single fibre, the chloride diffusion coefficient first decreased and then increased with the content, which was consistent with the results of Guo et al. [52]. Moreover, the fine PPF had a good inhibition effect on the microcrack, while the coarse PPF had a certain bridging effect on the macrocrack. The reasonable mixing ratio of coarse and fine fibres can effectively hinder the development of macro- and 
microcracks. The chloride ion penetration resistance of concrete was effectively improved by the composite addition of coarse and fine fibres. Afroughsabet et al. [36] investigated the effect of steel fibre and PPF on the chloride diffusivity of high-strength concrete. They found that the concrete with PPFs had lower chloride migration coefficient than the one without PPF. However, the chloride migration coefficient was greatly increased by adding those two kinds of fibres due to the increased conductivity of steel fibre. Liu et al. [54] established the diffusion model of chloride ion in fibrereinforced concrete according to Fick's second law. The predicted results of model analysis were close to the actual test results, as shown in Figure 7. The chloride ion penetration resistance of concrete was influenced by some factors (such as fibre diameter, fibre content, aggregate size, and aggregate volume content) through the sensitivity analysis of the important parameters in the diffusion model.

It can be seen that PPF can effectively improve the resistance to chloride ion penetration of concrete. The fibre diameter size, content, and proportion of coarse and fine fibres affect the resistance to chloride ion penetration. There are optimal technical parameters, but the results are different from each other, which is caused by the differences in concrete mix proportion, fibre quality, test methods, and so on.

2.6. Sulfate Resistance. Sulfate corrosion is the most common and extensive form of concrete chemical corrosion. Simultaneously, sulfate corrosion in concrete is a complex physical and chemical process. Sulfate ion infiltrates into the concrete and reacts with hydration products to produce expansive products, which cause concrete cracking and damage. The addition of PPF can improve the crack resistance of concrete and reduce the permeability of concrete. The PPF in concrete effectively prevents sulfate ion from concrete surface to the interior. Thus, the sulfate resistance of concrete can be improved by adding the PPF.

Behfarnia and Farshadfar [55] studied the sulfate resistance of PPF-reinforced self-consolidating concrete attacked by the $\mathrm{MgSO}_{4}$ solution with mass concentration of $5 \%$ and $10 \%$. The results showed that the addition of PPFs can significantly reduce the mass loss and compressive strength loss of the concrete immersed in $\mathrm{MgSO}_{4}$ solution, suggesting that the sulfate resistance of the concrete had been improved by adding PPFs. He et al. [56] established the diffusion model of sulfate ion in fibre-reinforced concrete (Figure 8) according to Fick's second law and reaction kinetics equation. The distribution of sulfate ion concentration in concrete was calculated based on the diffusion model. Mardani et al. [57] used the expansion rate of concrete to characterize the erosion effect of $\mathrm{Na}_{2} \mathrm{SO}_{4}$ solution on concrete. The PPF content by volume was $0.4 \%, 0.8 \%$, and $1 \%$ in their study. The results showed that the concrete with $1 \%$ PPF content has highest expansion rate. The concrete with $0.8 \%$ PPF content has the smallest expansion rate, which was only $76 \%$ of ordinary concrete. Ranjith et al. [32] adopt to study the influence of immersing age on the sulfate attack resistant of concrete. The concrete specimens were

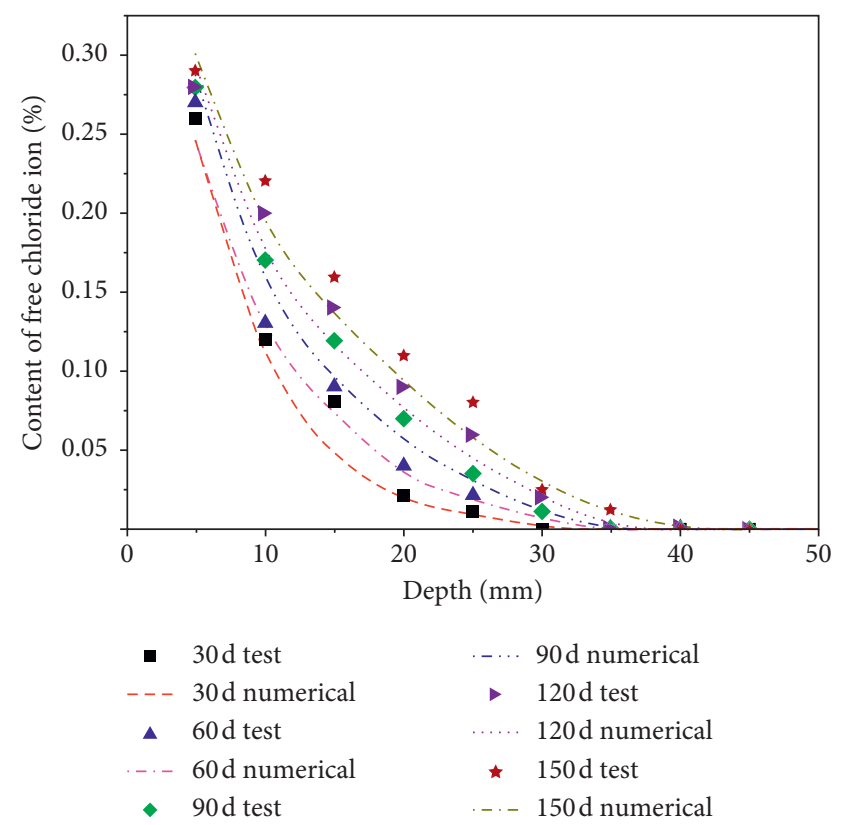

Figure 7: Comparison of model analysis results and measured results [54].
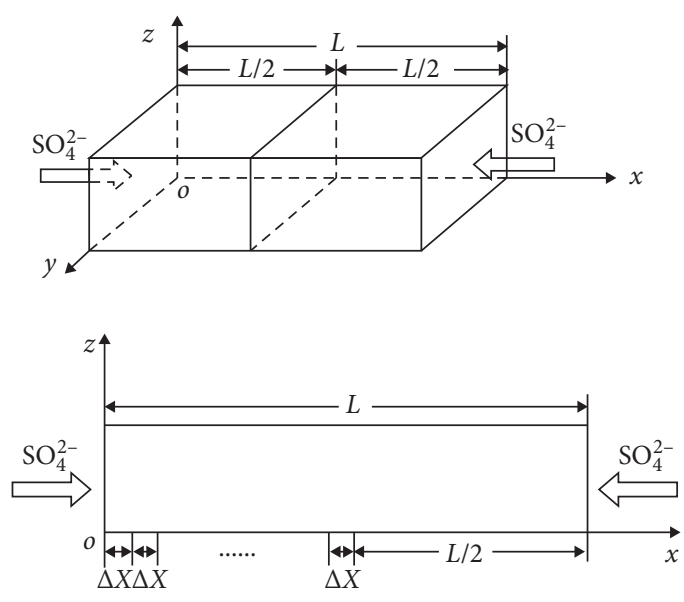

Figure 8: Schematic diagram of the sulfate erosion model [56].

immersed in $5 \%$ sodium sulfate solution for 30 days, 60 days, and 90 days, respectively. The loss rate of compressive strength showed a trend of first decreasing and then increasing within the range of $0-2 \%$ volume content. The concrete with $1.5 \%$ PPF has smallest loss rate of compressive strength.

At present, most of investigation results indicated that the addition of PPF can effectively reduce the penetration of sulfate ion in concrete. The penetration resistance of sulfate ion increased at first and then decreases with the increase of fibre content. Appropriate addition of fibre can reduce the porosity of concrete and hinder the sulfate ion transfer in the concrete. However, excessive content may increase the porosity of concrete and weaken the penetration of sulfate ion resistance [58]. 
2.7. Frost Resistance. The distribution of pore structure in concrete has an important impact on its freeze-thaw resistance. Water freezes in the pores produces frost heaving force, leading to cracks in concrete. As a result, strength and durability of concrete is decreased after freeze-thaw cycles. The incorporation of PPF can effectively increase the ability of concrete to resist freeze-thaw cycles. On the one hand, the incorporation of fibre reduces the porosity of concrete and reduces the water entering into the concrete. On the other hand, the development of cracks caused by frost heaving force is hindered by adding PPF in concrete.

Numerous researchers have been working on the freezethaw cycle characteristics of concrete with PPF. Karahan and Atiş [41] attempt to research the freeze-thaw resistance of PPF-reinforced concrete. They found that the freeze-thaw resistance of PPF-reinforced concrete was slightly increased compared to plain concrete. The freeze-thaw resistance of PPF-reinforced concrete can be significantly enhanced by adding fly ash as the active mineral admixture. Dong and Gao [59] investigated the effect of frost resistance of airport pavement concrete on fibre type and fibre content. The PPFreinforced concrete has better frost resistance than that of steel fibre-reinforced concrete. The best improvement on frost resistance was achieved by adding $1 \%$ PPF (by volume content) in the concrete. Nam et al. [60] compared the influence of PPF and polyvinyl alcohol fibre on the freezethaw cycle resistance of concrete. The freeze-thaw cycle resistance of two kinds of fibre-reinforced concrete was characterized by comparing the changes of concrete quality, compressive strength, and dynamic elastic modulus before and after freeze-thaw cycle. The results indicated that polyvinyl alcohol fibre can more effectively delay the mass loss, strength decline, and dynamic elastic modulus decrease of concrete caused by freeze-thaw cycle compared with PPF. This suggests that the vinyl alcohol fibre concrete has better freeze-thaw cycle resistance than that of PPF concrete. The freeze-thaw cycle resistance was affected by fibre dispersion and bond performance between fibre and cementitious material. The interfacial transition zones between PPF and cement overlap each other due to the poor dispersion of PPF in concrete, leading to the porosity of concrete, as shown in Figure 9. Wang et al. [61] studied the freeze-thaw cycle resistance of concrete with different PPF fibre contents $(0.1 \%, 0.3 \%$, and $0.5 \%)$, which were immersed in $3.5 \% \mathrm{NaCl}$ solution. The rates of mass and dynamic elastic modulus decrease of concrete after freeze-thaw cycle decrease with the fibre content. Moreover, the chloride content of concrete also increases with the increase of fibre content after freezethaw cycles. However, the chloride content of $0.1 \%$ fibre concrete is lower than the one without PPF after freeze-thaw cycles, suggesting that appropriate PPF content can hinder the chloride ion transfer in concrete.

The anti-freeze-thaw cycle ability of concrete is improved after adding polypropylene fibre. The PPF with different diameter has better improvement on frost resistance of concrete than that of single mixing. This attributes to the better dispersion of mixed fibre in concrete. Research results indicate that PPF can optimize the pore size distribution of concrete and reduce the water penetration in the

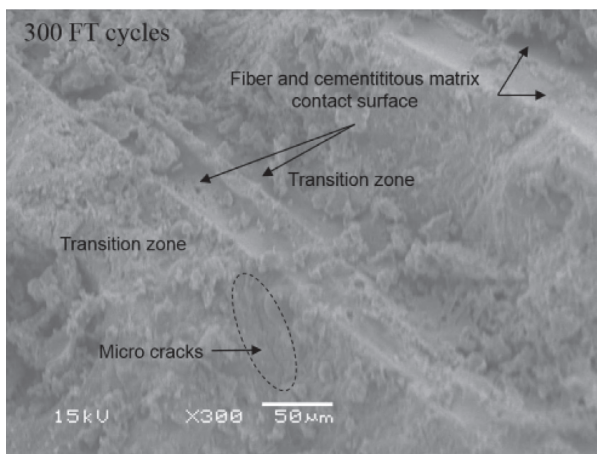

Figure 9: Microstructure of interface transition zone between polypropylene fibre and cement after 300 freeze-thaw cycles [60].

concrete. Meanwhile, the crack development under freezethaw cycle is effectively delayed after mixing with PPF in concrete.

2.8. Carbonation Resistance. Carbon dioxide enters into the concrete through pores and reacts with calcium hydroxide $(\mathrm{CH})$ to form calcium carbonate. The $\mathrm{pH}$ value of concrete decreases after carbonation due to the chemical reaction of carbon dioxide and $\mathrm{CH}$. For plain concrete, carbonation can fill the pores to a certain extent and improve the performance of concrete $[62,63]$. However, for steel-reinforced concrete, the carbonation may cause corrosion of reinforcement $[64,65]$. The passive film of steel bar will be destroyed under the joint action of water and air when carbonation reaches the position of steel bar. The addition of PPF can reduce the porosity and block the connection of pores of concrete. As a result, carbon dioxide is hindered into the concrete, which can effectively improve the anticarbonation ability of concrete.

The research results of Zhang et al. [66] showed that polypropylene fibre can improve the pore structure of concrete. The carbonation depth of concrete with PPF was only $0.80 \mathrm{~mm}$ at 28 days. Medina et al. [67] analysed the influence of on the porosity and carbonation performance of concrete with different fibre mass contents $(0-0.12 \%)$. The results indicated that PPF has good ability to control the generation and development of cracks. The crack area of concrete was first decreased and then increased with the fibre content. The concrete with $0.07 \%$ PPF content has the smallest crack area, and the carbonation depth of this concrete was decreased by $43 \%$. Mahmoud and Elkatatny [4] adopt to investigate the influence of different fibre mass contents $(0 \%, 0.125 \%, 0.25 \%$, and $0.375 \%)$ on the carbonation resistance of concrete. They found that the carbonation depth can be decreased by using PPF. The carbonation depth of concretes was gradually increased with the PPF content. The compressive strength and tensile strength of the concrete were increased after carbonation. Zhang and $\mathrm{Li}$ [68] investigated the effect of PPF volume fraction (from $0 \%$ to $0.12 \%$ ) on the carbonation resistance of concrete with fly ash and silica film. The results showed that the carbonation depth of concrete was decreased with the fibre content (Figure 10). Up to $37.5 \%$ reduction in carbonation depth can 


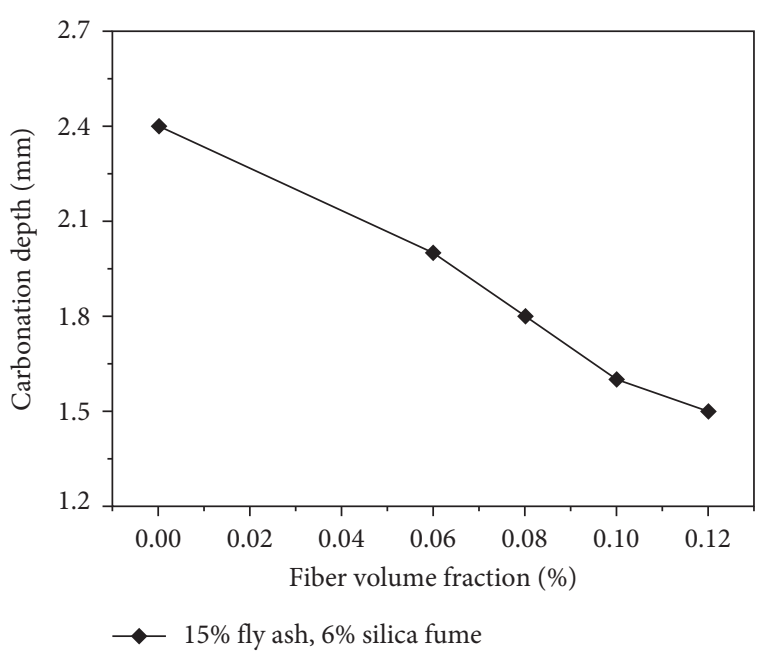

FIGURE 10: Effect of PPF volume fraction on carbonation depth of concrete [68].

be obtained for the concrete with $0.12 \% \mathrm{PPF}$ content. This is because the pore channels of concrete were decreased by using PPFs, which can block the pathway for $\mathrm{CO}_{2}$ diffusion.

The PPF can effectively reduce and inhibit the development of micropore in concrete. The carbon dioxide and water are prevented into the concrete, which delay the carbonation rate of concrete. The carbonation resistance of concrete can be significantly improved by adding proper content of PPF.

2.9. Fire Resistance. Fire is one of the most severe conditions for concrete structure in lifetime. The spalling is easily induced by the fire with high temperature. The strength and durability of concrete can be significantly decreased after exposed in fire, especially for high-performance concrete. Fire resistance is an essential performance for concrete structure design.

Some research has been devolved the fire resistance performance of PPF-reinforced concrete. Han et al. [69] reported that the fire resistance of concrete can be enhanced by using PPF. The concrete was heated from room temperature to $850^{\circ} \mathrm{C}$ for $40 \mathrm{~min}$. The results showed that the spalling was prevented when the volume content of PPF was more than $0.05 \%$. This is because the melting shape of PPFs can provide the microchannels for releasing the high internal vapour pressure in such high-temperature conditions. Peng et al. [70] tried to use PPFs in steel-reinforced reactive powder concrete. After exposed in temperature at $20^{\circ} \mathrm{C}-700^{\circ} \mathrm{C}$, the compressive strength of concrete was increased at the temperature no more than $400^{\circ} \mathrm{C}$, which might be due to further hydration of cement. However, the compressive strength was significantly decreased when the concrete exposed at the temperature more than $600^{\circ} \mathrm{C}$. Hussein et al. [71] investigated the fire resistance of concrete with PPFs and steel fibres. They found that the PPFs were disintegrated at temperature more than $400^{\circ} \mathrm{C}$ (Figure 11), which means the network channels were generated in concrete. This suggested that the spalling can be retarded at high temperature since the network channels discharged the interior vapour pressure. Moreover, the combination of PPFs and steel fibres can further increase the fire resistance of concrete. The corporation of those two type fibres can effectively avoid the spalling induced by the high temperature and minimum strength reduction.

When PPFs are added in concrete, the network channels appear in concrete due to the thermal decomposition of PPF. Those network channels have positive affect on inner heat release, which is beneficial for concrete against fire damage.

\section{Existing Problems and Countermeasures}

\subsection{Dispersion of Polypropylene Fibre in Cementitious} Materials. The dispersion of polypropylene fibre in concrete directly affects the durability of concrete. Well-distributed fibre can further improve the durability of concrete due to the better crack resistance. It is difficult to obtain excellent durability performance with low fibre content in concrete because of the hydrophobicity and small diameter of PPF. However, higher fibre content is easy to agglomerate in concrete. The cracks are more likely to occur and develop rapidly in areas without or less fibre. Once cracks are penetrated, it has very adverse impact on the durability of concrete [72-74]. At present, the dispersion of PPF can be increased by adding active agent or reactive powder. Active agent contains hydrophilic functional groups, which can form hydrogen bond with water molecules. The PPF has hydrophilic characteristics by adding active agent, such as water-reducing agent and dispersant, in mixing water. The dispersion of fibre in concrete was improved because of hydrophilic functional groups on the surface of PPF [75]. When reactive powder was used, the workability of concrete can be improved due to the "ball effect" of reactive powder, such as fly ash and nano- $\mathrm{SiO}_{2}[41,76]$. Additionally, some reactive powder, such as silica fume [68], nano- $\mathrm{TiO}_{2}$ [77], and nano- $\mathrm{CaCO}_{3}[78]$, can reduce the porosity and increase the strength of concrete. As a result, the durability of concrete is enhanced by adding those reactive powders into concrete.

3.2. Bonding Properties of Polypropylene Fibre Cement Matrix. $\mathrm{PPF}$ is an organic material with nonpolar, low surface energy, and hydrophobic. The PPF transfers force through the interface with the cement matrix. The PPF is separated from the cement before the ultimate stress is reached due to the weak bending between cement and fibre. As a result, it is not easy to achieve the best synergistic effect $[24,79]$. To this end, the bond performance between PPF and cement should be enhanced, so as to reduce the width of ITZ between PPF and cement. Some methods have been proposed. For example, the acid solution can corrode the surface and increase the roughness of the surface, so that the contact area between cement and PPF can be increased. The results showed that the roughness of PPF corroded by acid solution is obviously increased. The crack resistance of concrete is improved by adding the acid-treated PPF [30, 80, 81]. Another method is modifying the PPF using coupling agent due to the 


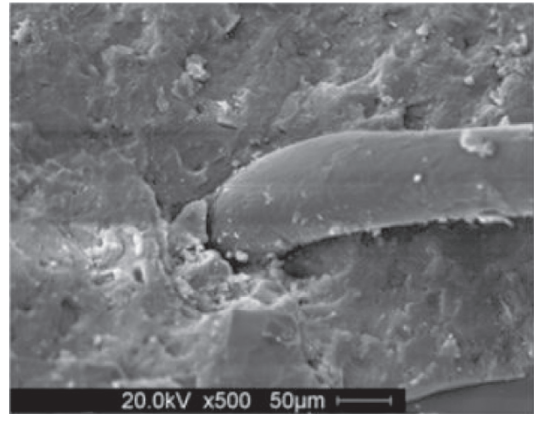

(a)

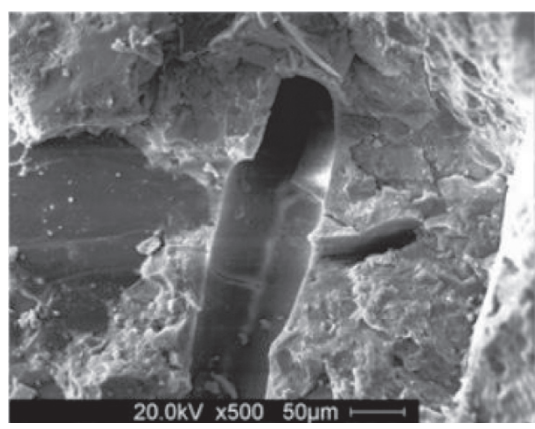

(b)

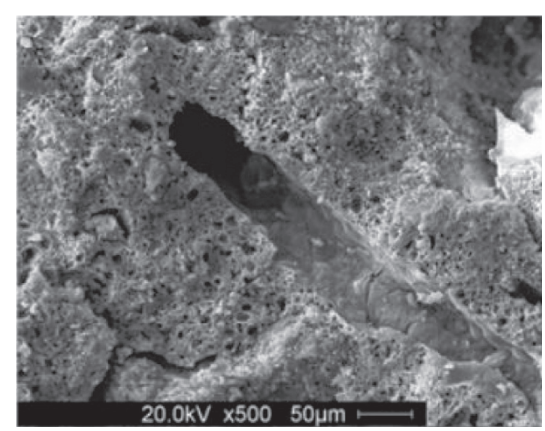

(c)

Figure 11: Microstructure of PPF melt channel with temperature in concrete [71]. (a) $20^{\circ} \mathrm{C}$, (b) $400^{\circ} \mathrm{C}$, and (c) $800^{\circ} \mathrm{C}$.

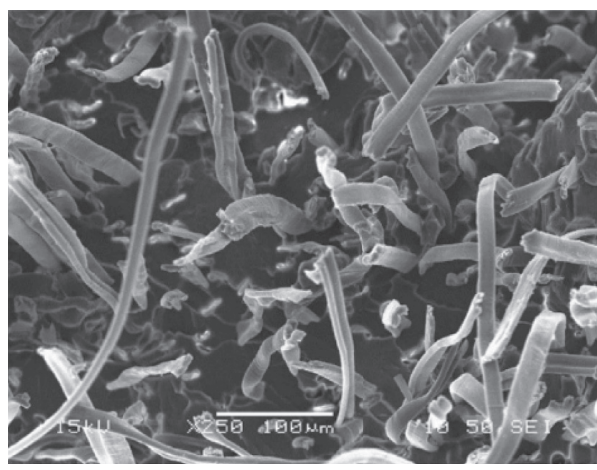

(a)

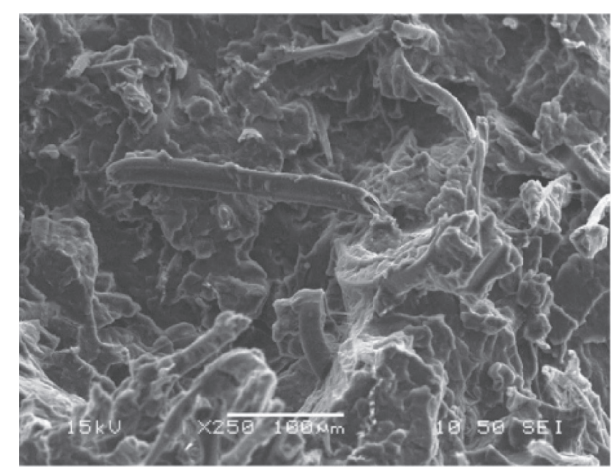

(b)

Figure 12: Effect of coupling agent on microstructure of polypropylene fibre-reinforced concrete [82]. (a) No coupling agent; (b) after adding coupling.

hydrophilic group and hydrophobic group in coupling agent. One end of the coupling agent molecule is combined with the fibre, and the other end is combined with the active group in the cement. The coupling agent acts as a "bridge" between the cement and the fibre, leading to the enhancement of the interfacial bonding property between the fibre and the cement $[82,83]$, as shown in Figure 12.

\section{Conclusions}

PPF has the excellent properties with light weight, high tensile strength, and good toughness. When adding PPFs, the concrete has lower porosity and higher crack resistance than the one without PPF. Therefore, it can reduce the transmission of water and harmful media in the concrete, leading to the enhancement of durability. The PPF-reinforced concrete has lower water absorption and better impermeability, chloride resistance, sulfate resistance, carbonation resistance, and fire resistance. The drying shrinkage can be reduced by adding PPF because the PPF has positive effect on preventing deformation. However, the creep of concrete was not reduced by using PPF due to the lower elastic modulus of PPF than the plain concrete. The durability of PPF-reinforced concrete can be further improved by combining with other fibre types, especially for the steel fibre.
However, the application of polypropylene fibre in concrete is limited because of the dispersion of fibre in concrete and the bond with cement. Those drawbacks can overcome by the fibre surface modification by using reactive powder, such as nano- $\mathrm{SiO}_{2}$ and nano- $\mathrm{CaCO}_{3}$. The bond performance with cement is another drawback for PPF application in concrete. This can be overcome by using fibre modified with acid or coupling agent. The ITZ between PPF and cement matrix can be significantly enhanced since the more hydration products deposited on the surface of modified PPFs. The durability of concrete can be significantly enhanced by using modified fibre.

\section{Future Research Prospects}

It should be noted that the improvement of concrete durability by PPF is affected by many factors, such as fibre diameter, length diameter ratio, mixing amount, mechanical properties, and modification methods. It is difficult to obtain a unified optimal technical parameter due to difference of research methods, curing conditions, parameter selection, and other aspects. According to the current research status, the future research prospects are given as follows:

(1) Synergism between polypropylene fibre and other fibres 
The PPF has some limitations in improving the durability of concrete. The combination of PPF and other fibres (such as steel fibre) can achieve better durability of concrete. Therefore, the enhancement principle of composite fibre on concrete performance should be further studied. The pore size distribution in concrete, cracks development process, and the interface transition zone (ITZ) between fibres and cement mortar should be further studied. Some advanced characterization methods, such as mercury intrusion porosimetry analysis, CT scan, and nanoindentation, may work for those studies. In addition, when PPFs and steel fibres are used in concrete, the rust of steel fiber should be prevented, which can avoid the degradation of concrete performance caused by steel fiber rust. On those bases, ideal enhancing effect can be achieved under optimizing the combination parameters. For highstrength and high-performance concrete, the optimal combination parameters can effectively reduce the shrinkage and cracks of concrete at early age. The early crack resistance test of fibre-reinforced concrete may be carried out to characterize the influence of concrete shrinkage on concrete cracking risk. The dry shrinkage and creep of fibre-reinforced concrete may be conducted for the further study, which is helpful to probe the effect of fibre synergy on the long-term volume stability of high-strength and high-performance concrete. It is great significance for the development of high-strength and highperformance concrete to study the synergistic effect of composite fibre.

(2) Durability of concrete under multicondition coupling action

At present, most of the works aim for the influence of the single index and parameter on the durability of PPF-reinforced concrete. However, concrete is often affected by two or more combination conditions in actual situation. Future work should concern the durability characterization in the actual environment condition for the PPF-reinforced concrete. For example, the permeability and wear resistance should be considered when the concrete is used in pavement. The deterioration of concrete caused by the combination of permeability, chloride ion permeability, and dry wet cycle should be concerned for the concrete used in dock. For the cold region, frost resistance should also be added to these combinations. Moreover, the future research should be focused on the deterioration mechanism of concrete with PPFs caused by the combination of the durability indexes. Due to the standard test is difficult to fully reflect the real working condition of concrete, the numerical simulation and field test should be combined with laboratory characterization analysis. In this way, the investigators will fully understand the deterioration mechanism of concrete under the combination of multiple factors. In addition, weatherability of PPF should be considered once the water and harmful ions permeate into concrete. Those advices are helpful to reveal the influence mechanism of PPF and concrete performance, which can provide theoretical basis for engineering practice.

(3) Establishing the relationship between modified PPF and concrete performance

The surface modification method can effectively improve the bonding performance between PPF and cement. It needs to solve the problem of the ITZ between PPF and cement mortar. The amphiphilic modifier is acquired for treating PPF. Our research group is developing a new modifier inspired by tea stains. The modified fibre can actively capture calcium ions and induce local mineralization. More hydration products are deposited on the surface of fibre. The ITZ between fibre and cement mortar can be enhanced by using the modifier-treated fibres, which is helpful to the formation of cement paste microstructure. The performance of concrete can be further enhanced by adding modified fibres. To this end, the influence of modified fibre on the hardening process of cement paste is analysed to in-depth understanding of the internal relationship between fibre and concrete. Meanwhile, the proportion of cement can be reduced by adding modified fibres under the same performance requirements of concrete. In this case, the mix proportion needs to be redesigned to meet the performance requirements. On this basis, the relationship between hardened paste and macroproperties should be studied to the formation of parameter optimization and control based on the performance requirements of concrete.

\section{Conflicts of Interest}

The authors declare no conflicts of interest.

\section{Authors' Contributions}

Yanzhu Liu was responsible for literature search and writing the original draft. Liang Wang carried out conceptualization and reviewed and edited the article. Ke Cao conducted investigation. Lei Sun involved in literature search.

\section{Acknowledgments}

This work was supported by the Natural Science Foundation of Universities in Anhui Province (KJ2019A0129), Key Research and Development Project of Anhui Province (201904a07020081), Anhui Province Natural Science Foundation (2008085QE244), and China Postdoctoral Science Foundation (2020M681988). 


\section{References}

[1] D. Pérez-Rocha, A. B. Morales-Cepeda, F. Navarro-Pardo, T. Lozano-Ramírez, and P. G. LaFleur, "Carbon fiber composites of pure polypropylene and maleated polypropylene blends obtained from injection and compression moulding," International Journal of Polymer Science, vol. 2015, Article ID 493206, 8 pages, 2015.

[2] Y. Tapiero, B. L. Rivas, and J. Sánchez, "Activated polypropylene membranes with ion-exchange polymers to transport chromium ions in water," Journal of the Chilean Chemical Society, vol. 64, no. 4, pp. 4597-4606, 2019.

[3] B. Ali, L. A. Qureshi, and R. Kurda, "Environmental and economic benefits of steel, glass, and polypropylene fiber reinforced cement composite application in jointed plain concrete pavement," Composites Communications, vol. 22, Article ID 100437, 2020.

[4] A. A. Mahmoud and S. Elkatatny, "Improving class G cement carbonation resistance for applications of geologic carbon sequestration using synthetic polypropylene fiber," Journal of Natural Gas Science and Engineering, vol. 76, Article ID 103184, 2020.

[5] T. Yamamoto and Y. Ota, "Creating a laminated carbon fiberreinforced thermoplastic using polypropylene and nylon with a polypropylene colloid," Composite Structures, vol. 255, Article ID 113038, 2021.

[6] D. Bracho, V. N. Dougnac, H. Palza, and R. Quijada, "Functionalization of silica nanoparticles for polypropylene nanocomposite applications," Journal of Nanomaterials, vol. 2012, Article ID 263915, 8 pages, 2012.

[7] I. Hussain, B. Ali, T. Akhtar, M. S. Jameel, and S. S. Raza, "Comparison of mechanical properties of concrete and design thickness of pavement with different types of fiber-reinforcements (steel, glass, and polypropylene)," Case Studies in Construction Materials, vol. 13, Article ID e00429, 2020.

[8] D. Shen, X. Liu, X. Zeng, X. Zhao, and G. Jiang, "Effect of polypropylene plastic fibers length on cracking resistance of high performance concrete at early age," Construction and Building Materials, vol. 244, Article ID 117874, 2020.

[9] P. Smarzewski, "Comparative fracture properties of four fibre reinforced high performance cementitious composites," Materials, vol. 13, no. 11, p. 2612, 2020.

[10] Z. Çelik and A. F. Bingöl, "Mechanical properties and postcracking behavior of self-compacting fiber reinforced concrete," Structural Concrete, vol. 21, no. 5, pp. 2124-2133, 2020.

[11] Y. Qin, H. Wu, Y. Zheng, W. Wang, and Z. Yi, "Microscopic texture of polypropylene fiber-reinforced concrete with X-ray computed tomography," Advances in Civil Engineering, vol. 2019, Article ID 2386590, 9 pages, 2019.

[12] D. Li and S. Liu, "Macro polypropylene fiber influences on crack geometry and water permeability of concrete," Construction and Building Materials, vol. 231, Article ID 117128, 2020.

[13] J. Wang, Q. Dai, R. Si, and S. Guo, "Mechanical, durability, and microstructural properties of macro synthetic polypropylene (PP) fiber-reinforced rubber concrete," Journal of Cleaner Production, vol. 234, pp. 1351-1364, 2019.

[14] M. U. Rashid, "Experimental investigation on durability characteristics of steel and polypropylene fiber reinforced concrete exposed to natural weathering action," Construction and Building Materials, vol. 250, Article ID 118910, 2020.
[15] K. Behfarnia and A. Behravan, "Application of high performance polypropylene fibers in concrete lining of water tunnels," Materials \& Design, vol. 55, pp. 274-279, 2014.

[16] R. Muntean, C. Cazacu, P. Mizgan, T. Galatanu, and F. Tamas, "Practical applications of dispersely reinforced concrete with polypropylene fibers: beams," Procedia Engineering, vol. 181, pp. 285-292, 2017.

[17] Y. Pang, L. Cai, and J. Zhong, "Seismic performance evaluation of fiber-reinforced concrete bridges under near-fault and far-field ground motions," Structures, vol. 28, pp. 1366$1383,2020$.

[18] S. H. Jung, Y. C. Choi, and S. Choi, "Use of ternary blended concrete to mitigate thermal cracking in massive concrete structures-a field feasibility and monitoring case study," Construction and Building Materials, vol. 137, pp. 208-215, 2017.

[19] Z. Zhao, K. Wang, D. A. Lange, H. Zhou, W. Wang, and D. Zhu, "Creep and thermal cracking of ultra-high volume fly ash mass concrete at early age," Cement and Concrete Composites, vol. 99, pp. 191-202, 2019.

[20] M. K. Saeed, M. K. Rahman, and M. H. Baluch, "Influence of steel and polypropylene fibers on cracking due to heat of hydration in mass concrete structures," Structural Concrete, vol. 20, no. 2, pp. 808-822, 2018.

[21] G. M. S. Islam and S. Das, "Evaluating plastic shrinkage and permeability of polypropylene fiber reinforced concrete," International Journal of Sustainable Built Environment, vol. 5, pp. 345-354, 2016.

[22] H. Ma and Z. Zhang, "Paving an engineered cementitious composite (ECC) overlay on concrete airfield pavement for reflective cracking resistance," Construction and Building Materials, vol. 252, Article ID 119048, 2020.

[23] A. Mansourian, S. Hashemi, M. R. M. Aliha, and M. Aliha, "Evaluation of pure and mixed modes (I/III) fracture toughness of Portland cement concrete mixtures containing reclaimed asphalt pavement," Construction and Building Materials, vol. 178, pp. 10-18, 2018.

[24] H. Guo, L. Jiang, J. Tao, Y. Chen, Z. Zheng, and B. Jia, "Influence of a hybrid combination of steel and polypropylene fibers on concrete toughness," Construction and Building Materials, vol. 275, Article ID 122132, 2021.

[25] P. Smarzewski, "Study of toughness and macro/micro-crack development of fibre-reinforced ultra-high performance concrete after exposure to elevated temperature," Materials, vol. 12, no. 8, p. 1210, 2019.

[26] Y. Chen, G. Cen, and Y. Cui, "Comparative analysis on the anti-wheel impact performance of steel fiber and reticular polypropylene synthetic fiber reinforced airport pavement concrete under elevated temperature aging environment," Construction and Building Materials, vol. 192, pp. 818-835, 2018.

[27] Y. Chen, G. Cen, and Y. Cui, "Comparative study on the effect of synthetic fiber on the preparation and durability of airport pavement concrete," Construction and Building Materials, vol. 184, pp. 34-44, 2018.

[28] P. Smarzewski and D. Barnat-hunek, "Effect of fiber hybridization on durability related properties of ultra-high performance concrete," International Journal of Concrete Structures and Materials, vol. 11, no. 2, pp. 315-325, 2017.

[29] Y. Li and D. Zhang, "Effect of lateral restraint and inclusion of polypropylene and steel fibers on spalling behavior, pore pressure, and thermal stress in ultra-high-performance concrete (UHPC) at elevated temperature," Construction and Building Materials, vol. 271, Article ID 121879, 2021. 
[30] M. V. Bhogone and K. V. L. Subramaniam, "Early-age tensile constitutive relationships for steel and polypropylene fiber reinforced concrete," Engineering Fracture Mechanics, vol. 244, Article ID 107556, 2021.

[31] X. Liu, T. Wu, X. Yang, and H. Wei, "Properties of selfcompacting lightweight concrete reinforced with steel and polypropylene fibers," Construction and Building Materials, vol. 226, pp. 388-398, 2019.

[32] S. Ranjith, R. Venkatasubramani, and V. Sreevidya, "Comparative study on durability properties of engineered cementitious composites with polypropylene fiber and glass fiber," Archives of Civil Engineering, vol. 63, no. 4, pp. 83-101, 2017.

[33] G. W. Leong, K. H. Mo, Z. P. Loh, and Z. Ibrahim, "Mechanical properties and drying shrinkage of lightweight cementitious composite incorporating perlite microspheres and polypropylene fibers," Construction and Building Materials, vol. 246, Article ID 118410, 2020.

[34] D. Saje, B. Bandelj, J. Šušteršič, J. Lopatič, and F. Saje, "Shrinkage of polypropylene fiber-reinforced high-performance concrete," Journal of Materials in Civil Engineering, vol. 23, no. 7, pp. 941-952, 2011.

[35] F. Alrshoudi, H. Mohammadhosseini, M. M. Tahir et al., "Drying shrinkage and creep properties of prepacked aggregate concrete reinforced with waste polypropylene fibers," Journal of Building Engineering, vol. 32, Article ID 101522, 2020.

[36] V. Afroughsabet, L. Biolzi, and P. J. M. Monteiro, "The effect of steel and polypropylene fibers on the chloride diffusivity and drying shrinkage of high-strength concrete," Composites Part B: Engineering, vol. 139, pp. 84-96, 2018.

[37] R. Vrijdaghs, M. di Prisco, and L. Vandewalle, "Uniaxial tensile creep of a cracked polypropylene fiber reinforced concrete," Materials and Structures, vol. 51, no. 1, pp. 1-12, 2018.

[38] V. Lima, D. C. T. Cardoso, and F. A. Silva, "Flexural creep behavior of steel and polypropylene fiber reinforced concrete," in Proceedings of the 10th International Conference on Fracture Mechanics of Concrete and Concrete Structures, p. 7, July 2019.

[39] F. Aslani and S. Nejadi, "Creep and shrinkage of self-compacting concrete with and without fibers," Journal of Advanced Concrete Technology, vol. 11, no. 10, pp. 251-265, 2013.

[40] Q. Zhao, J. Yu, G. Geng, J. Jiang, and X. Liu, "Effect of fiber types on creep behavior of concrete," Construction and Building Materials, vol. 105, pp. 416-422, 2016.

[41] O. Karahan and C. D. Atiş, "The durability properties of polypropylene fiber reinforced fly ash concrete," Materials \& Design, vol. 32, no. 2, pp. 1044-1049, 2011.

[42] Z. Yuan and Y. Jia, "Mechanical properties and microstructure of glass fiber and polypropylene fiber reinforced concrete: an experimental study," Construction and Building Materials, vol. 266, Article ID 121048, 2021.

[43] F. Liu, W. Ding, and Y. Qiao, “An experimental investigation on the integral waterproofing capacity of polypropylene fiber concrete with fly ash and slag powder," Construction and Building Materials, vol. 212, pp. 675-686, 2019.

[44] V. Afroughsabet and T. Ozbakkaloglu, "Mechanical and durability properties of high-strength concrete containing steel and polypropylene fibers," Construction and Building Materials, vol. 94, pp. 73-82, 2015.

[45] P. Matar and J. J. Assaad, "Concurrent effects of recycled aggregates and polypropylene fibers on workability and key strength properties of self-consolidating concrete," Construction and Building Materials, vol. 199, pp. 492-500, 2019.

[46] I. Bentegri, O. Boukendakdji, E.-H. Kadri, T. T. Ngo, and H. Soualhi, "Rheological and tribological behaviors of polypropylene fiber reinforced concrete," Construction and Building Materials, vol. 261, Article ID 119962, 2020.

[47] S. Elkatatny, R. Gajbhiye, A. Ahmed, and A. A. Mahmoud, "Enhancing the cement quality using polypropylene fiber," Journal of Petroleum Exploration and Production Technology, vol. 10, no. 3, pp. 1097-1107, 2019.

[48] Y. Li, Y. Zhang, E.-H. Yang, and K. H. Tan, "Effects of geometry and fraction of polypropylene fibers on permeability of ultra-high performance concrete after heat exposure," Cement and Concrete Research, vol. 116, pp. 168-178, 2019.

[49] A. A. Ramezanianpour, M. Esmaeili, S. A. Ghahari, and M. H. Najafi, "Laboratory study on the effect of polypropylene fiber on durability, and physical and mechanical characteristic of concrete for application in sleepers," Construction and Building Materials, vol. 44, pp. 411-418, 2013.

[50] Z. Q. Guo, "Experimental study on the impermeability of multi-scale polypropylene fibre concrete," Master thesis, Chongqing University, Chongqing, China, 2018.

[51] J. Liu, Y. Jia, and J. Wang, "Experimental study on mechanical and durability properties of glass and polypropylene fiber reinforced concrete," Fibers and Polymers, vol. 20, no. 9, pp. 1900-1908, 2019.

[52] Q. S. Guo, Q. Chen, Z. W. Jiang, B. He, and C. P. Xu, "Effects of fibres on permeability of high performance concrete for deep tunnels," China Concrete and Cement Products, vol. 12, pp. 48-51, 2019, in Chinese.

[53] S. M. Liu and H. Y. Hu, "Study of mechanical and resistance to chloride ion penetration properties of hybrid polypropylene fibre reinforced concrete," Engineering Journal of Wuhan University, vol. 52, pp. 131-138, 2019, in Chinese.

[54] J. Liu, Y. Jia, and J. Wang, "Calculation of chloride ion diffusion in glass and polypropylene fiber-reinforced concrete," Construction and Building Materials, vol. 215, pp. 875-885, 2019.

[55] K. Behfarnia and O. Farshadfar, "The effects of pozzolanic binders and polypropylene fibers on durability of SCC to magnesium sulfate attack," Construction and Building Materials, vol. 38, pp. 64-71, 2013.

[56] R. He, Y. W. Tan, S. Wang, and D. Li, "Numerical simulation of sulfate diffusion process in polypropylene fibre concrete," Bulletin of the Chinese Ceramic Society, vol. 37, pp. 232-240, 2018, in Chinese.

[57] A. Mardani, S. Özen, and M. G. Altun, "Durability performance and dimensional stability of polypropylene fiber reinforced concrete," Journal of Green Building.vol. 13, pp. 20-41, 2018.

[58] L. Guo, Y. Wu, F. Xu et al., "Sulfate resistance of hybrid fiber reinforced metakaolin geopolymer composites," Composites Part B: Engineering, vol. 183, Article ID 107689, 2020.

[59] X. Dong and J. Gao, "Effects of fiber type and fiber volume content on frost resistance of fiber-reinforced concrete in airport pavement," in Proceedings of the Third International Conference on Transportation Engineering (ICTE), pp. 15241529, Chengdu, China, July 2011.

[60] J. Nam, G. Kim, B. Lee, R. Hasegawa, and Y. Hama, "Frost resistance of polyvinyl alcohol fiber and polypropylene fiber reinforced cementitious composites under freeze thaw cycling," Composites Part B: Engineering, vol. 90, pp. 241-250, 2016. 
[61] C. Wang, Z. Guo, and D. Niu, "Influence of the fiber volume content on the durability-related properties of polypropylenefiber-reinforced concrete," Sustainability, vol. 12, no. 2, p. 549, 2020.

[62] R. Andersson, H. Stripple, T. Gustafsson, and C. Ljungkrantz, "Carbonation as a method to improve climate performance for cement based material," Cement and Concrete Research, vol. 124, Article ID 105819, 2019.

[63] L. Qin, X. Gao, and T. Chen, "Influence of mineral admixtures on carbonation curing of cement paste," Construction and Building Materials, vol. 212, pp. 653-662, 2019.

[64] M. Otieno, J. Ikotun, and Y. Ballim, "Experimental investigations on the influence of cover depth and concrete quality on time to cover cracking due to carbonation-induced corrosion of steel in RC structures in an urban, inland environment," Construction and Building Materials, vol. 198, pp. 172-181, 2019.

[65] A. Belda, K. De Weerdt, K. Hornbostel, and M. Rica, "Carbonation-induced corrosion: investigation of the corrosion onset," Construction and Building Materials.vol. 162, pp. 847-856, 2018.

[66] W. Zhang, C. Yin, F. Ma, and Z. Huang, "Mechanical properties and carbonation durability of engineered cementitious composites reinforced by polypropylene and hydrophilic polyvinyl alcohol fibers," Materials, vol. 11, no. 7, p. $1147,2018$.

[67] N. F. Medina, G. Barluenga, and F. Hernández-Olivares, "Enhancement of durability of concrete composites containing natural pozzolans blended cement through the use of polypropylene fibers," Composites. Part B Engineering.vol. 61, pp. 214-221, 2014.

[68] P. Zhang and Q.-f. Li, "Effect of polypropylene fiber on durability of concrete composite containing fly ash and silica fume," Composites Part B: Engineering, vol. 45, no. 1, pp. 1587-1594, 2013.

[69] C.-G. Han, Y.-S. Hwang, S.-H. Yang, and N. Gowripalan, "Performance of spalling resistance of high performance concrete with polypropylene fiber contents and lateral confinement," Cement and Concrete Research, vol. 35, no. 9, pp. 1747-1753, 2005.

[70] G.-F. Peng, Y.-R. Kang, Y.-Z. Huang, X.-P. Liu, and Q. Chen, "Experimental research on fire resistance of reactive powder concrete," Advances in Materials Science and Engineering, vol. 2012, Article ID 860303, 6 pages, 2012.

[71] R. J. Hussein, N. A.-A. Alwash, and J. J. Alwash, "Combining polypropylene and steel fiber to reduce spalling of reactive powder concrete subjected to fire flame," in Proceedings of the 2nd International Conference on Materials Engineering o Science (IConMEAS 2019), March 2020, Article ID 20111.

[72] V. W. Y. Tam and C. M. Tam, "Assessment of durability of recycled aggregate concrete produced by two-stage mixing approach," Journal of Materials Science, vol. 42, no. 10, pp. 3592-3602, 2007.

[73] G. Lavanya and J. Jegan, "Durability study on high calcium fly ash based geopolymer concrete," Advances in Materials Science and Engineering, vol. 2015, Article ID 731056, 7 pages, 2015.

[74] V. M. Sounthararajan and A. Sivakumar, "Durability evaluation in concrete using cracked permeability and chloride permeability tests," Advances in Materials Science and Engineering, vol. 2013, Article ID 754027, 8 pages, 2013.

[75] E. Jia, H. Mou, Z. Liu et al., "Surface hydrophilic modification of polypropylene fibers and their application in fiber- reinforced cement-based materials," Journal of Macromolecular Science, Part B, vol. 60, no. 4, pp. 286-298, 2020.

[76] F. U. A. Shaikh, Y. Shafaei, and P. K. Sarker, "Effect of nano and micro-silica on bond behaviour of steel and polypropylene fibres in high volume fly ash mortar," Construction and Building Materials, vol. 115, pp. 690-698, 2016.

[77] D. Wang, L. Xuan, G. Han, A. H. H. Wong, Q. Wang, and W. Cheng, "Preparation and characterization of foamed wheat straw fiber/polypropylene composites based on modified nano- $\mathrm{TiO}_{2}$ particles," Composites Part A: Applied Science and Manufacturing, vol. 128, Article ID 105674, 2020.

[78] J. Feng, F. Yang, and S. Qian, "Improving the bond between polypropylene fiber and cement matrix by nano calcium carbonate modification," Construction and Building Materials, vol. 269, Article ID 121249, 2021.

[79] J.-W. Han, J.-H. Jeon, and C.-G. Park, "Bond characteristics of macro polypropylene fiber in cementitious composites containing nanosilica and styrene butadiene latex polymer," International Journal of Polymer Science, vol. 2015, Article ID 207456, 9 pages, 2015.

[80] C. Ning, G. Z. Li, S. Zhang, and H. Y. Yuan, "Modification of polypropylene fibers by acrylic acid and its influence on the mechanical property of cement mortar," Advanced Materials Research, vol. 168-170, pp. 1459-1462, 2010.

[81] M. Mohamadi, J. A. Mohandesi, and M. Homayonifar, "Fatigue behavior of polypropylene fiber reinforced concrete under constant and variable amplitude loading," Journal of Composite Materials, vol. 47, no. 26, pp. 3331-3342, 2013.

[82] R. Várdai, T. Lummerstorfer, C. Pretschuh et al., "Reinforcement of PP with polymer fibers: effect of matrix characteristics, fiber type and interfacial adhesion," Polymer, vol. 190, Article ID 122203, 2020.

[83] J. Yang, R. Wang, and Y. Zhang, "Influence of dually mixing with latex powder and polypropylene fiber on toughness and shrinkage performance of overlay repair mortar," Construction and Building Materials, vol. 261, Article ID 120521, 2020. 